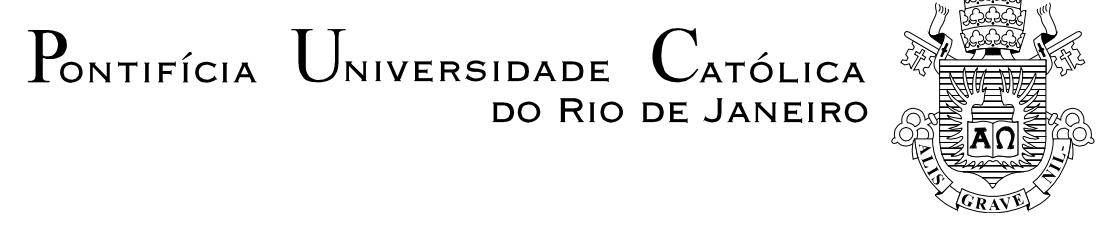

Nádia do Amor Divino de Lima

\title{
OPERADORES LOGÍSTICOS E SEUS CLIENTES: UM ESTUDO EMPÍRICO
}

Dissertação de Mestrado

Dissertação apresentada como requisito parcial para obtenção do grau de Mestre pelo Programa de Pós-graduação em Engenharia de Produção do Departamento de Engenharia Industrial da PUCRio.

Orientador: Prof. Luiz Felipe Roris Rodriguez Scavarda do Carmo 
Nádia do Amor Divino de Lima

\section{Operadores Logísticos e seus clientes: um estudo empírico}

Dissertação apresentada como requisito parcial para obtenção do título de Mestre pelo Programa de PósGraduação em Engenharia de Produção da PUC-Rio. Comissão Examinadora abaixo assinada.

Prof. Luiz Felipe Roris Rodriguez Scavarda do Carmo Orientador Departamento de Engenharia Industrial - PUC-Rio

Prof. Nélio Pizzolato Departamento de Engenharia Industrial - PUC-Rio

Prof. Hannes Winkler Fraunhofer IML

Prof. José Eugenio Leal Coordenador Setorial do Centro Técnico Científico - PUC-Rio

Rio de Janeiro, 25 de maio de 2012. 
Todos os direitos reservados. É proibida a reprodução total ou parcial do trabalho sem autorização da universidade, do autor e do orientador.

\section{Nádia do Amor Divino de Lima}

Graduou-se em Engenharia Química na Universidade Federal Rural do Rio de Janeiro em 2000. Exerceu a função de profissional de Logística e Supply Chain Management em empresas de grande porte durante 10 anos no Rio de Janeiro.

Ficha Catalográfica

Nádia do Amor Divino de Lima

Operadores logísticos e seus clientes: um estudo empírico / Nádia do Amor Divino de Lima ; orientador: Luiz Felipe Roris Rodriguez Scavarda do Carmo. - 2012.

$86 \mathrm{f.} ; 30 \mathrm{~cm}$

Dissertação (mestrado)-Pontifícia Universidade

Católica do Rio de Janeiro, Departamento de Engenharia Industrial, 2012.

Inclui bibliografia

1. Engenharia Industrial - Teses. 2. Prestadores de serviços logísticos. 3. Logística. 4. Terceirização. 5. Partys Longistics. 6. Cadeia de suprimentos. 7. Parceria. I. Carmo, Luiz Felipe Roris Rodriguez Scavarda do. II. Pontifícia Universidade Católica do Rio de Janeiro. Departamento de Engenharia Industrial. III. Título. 


\section{Agradecimentos}

À Deus, por essa conquista.

À minha mãe, ao meu marido e aos meus filhos pelo apoio, pelo carinho e pela confiança.

Aos meus colegas de turma pela amizade, em especial às minhas queridas amigas Adriana e Luíza.

Ao meu Orientador, Prof. Luiz Felipe Scavarda, pelas valiosas contribuições para o trabalho, pela dedicação, confiança, compreensão e disponibilidade depositada nesse trabalho.

Aos professores e funcionários do DEI da PUC-Rio, pelo apoio e infraestrutura.

À CAPES, pelo auxílio durante o curso. 


\section{Resumo}

de Lima, Nádia do Amor Divino; do Carmo, Luiz Felipe Roris Rodriguez Scavarda (Orientador). Operadores logísticos e seus clientes: um estudo empírico. Rio de Janeiro, 2012. 86p. Dissertação de Mestrado Departamento de Engenharia Industrial. Pontifícia Universidade Católica do Rio de Janeiro.

Considerando o crescimento e a importância da terceirização das atividades logística no Rio de Janeiro e a carência de estudos mais específicos de operadores logísticos no Brasil, a presente dissertação tem como objetivo analisar os prestadores de serviços logísticos e seus contratantes no Grande Rio. Para isso foram consideradas seis empresas neste estudo, três delas contratantes de serviços logísticos e outras três prestadores de serviços logísticos. Esta análise contempla fatores como a motivação para contratação, as atividades contratadas, o tempo de contrato, o processo de contratação, os indicadores de desempenho utilizados e as expectativas futuras consideradas por parte dos prestadores de serviços logísticos e das empresas contratantes, incluindo as vantagens e desvantagens destes relacionamentos em uma cadeia de suprimentos.

\section{Palavras-chave}

Prestadores de Serviços Logísticos; Logística; Terceirização; Partys Logistics; Cadeia de Suprimentos; Parceria. 


\section{Abstract}

de Lima, Nádia do Amor Divino; do Carmo, Luiz Felipe Roris Rodriguez Scavarda (advisor). Logistic service providers and their customers: an empirical study. Rio de Janeiro, 2012. 86p. MSc. Dissertation Departamento de Engenharia Industrial. Pontifícia Universidade Católica do Rio de Janeiro.

Considering the growth and importance of the outsourcing of logistics activities in Rio de Janeiro and the lack of more specific studies of logistics operators in Brazil, this master thesis aims to analyze the logistics service providers and their contractors in the metropolitan area of Rio de Janeiro. Six companies were considered in this study, three contractors and three logistics service providers. This analysis includes factors as motivation for hiring, contracted activities, length of contract, the contracting process, the performance indicators used and the future expectations considered by the logistics service providers and contractors, including the benefits and disadvantages of these relationships in a supply chain.

\section{Keywords}

Logistic Service Providers; Logistics; Outsourcing; Partys Logistics; Supply Chain; Partnership. 


\section{Sumário}

$\begin{array}{ll}\text { 1. Introdução } & 10\end{array}$

2. Fundamentação Teórica 12

2.1 Supply Chain Management (SCM) - Gestão da Cadeia de

$\begin{array}{ll}2.2 \text { Tipos de Relacionamento } & 18\end{array}$

2.3 Integração da Cadeia/Agente Integrador $\quad 21$

2.4 A Tercerização Logística 23

2.5 O Prestador de Serviços Logísticos (PSL) 25

2.5.1. Os Partys Logistics $\quad 29$

2.5.2. Vantagens e Desvantagens da Contratação dos PSLs 31

2.5.3. Prestador de Serviço Logístico X Operador Logístico 33

3. Método de Pesquisa 36

4. Contratantes $\quad 37$

4.1. Empresa Contratante A - ECA 37

4.2. Empresa Contratante B - ECB 40

4.3. Empresa Contratante C - ECC 42

4.4. Síntese Empresas Contratantes 44

5. Contratados 46

5.1. Prestador de Serviço 1 - PS1 46

5.2. Prestador de Serviço 2 - PS2 49

5.3. Prestador de Serviço 3 - PS3 51

5.4. Síntese Prestadores de Serviços Logísticos 53

6. Análise e Expectativas Contratantes X Contratados 58

6.1. Os Contratantes $\quad 58$

6.2. Os Contratados $\quad 60$

7. Conclusão 63

$\begin{array}{ll}\text { Referências Bibliográficas } & 65\end{array}$

Apêndice 01 - Vantagem Competitiva $\quad 70$

Apêndice 02 - Questionário Contratante - Cliente 71

Apêndice 03 - Questionário Contratado - PSL 78 


\section{Lista de figuras}

Figura 1: Áreas corporativas SCM

Figura 2: Esquema da relação de compradores e fornecedores na Gestão da Cadeia de Suprimentos 15

Figura 3: Tipos de Relacionamentos 19

Figura 4: Características das parcerias 20 


\section{Lista de tabelas}

Tabela 1: Razões para a terceirização dos serviços logísticos

Tabela 2: Critérios para analisar e avaliar os PSLs no processo de contratação 28

Tabela 3: Partys Logistics $\quad 30$

Tabela 4: Atividades oferecidas pelos PSL 31

Tabela 5: Resumo das Características das empresas contratantes estudadas 45

Tabela 6: Resumo das características dos PSLs estudados I 54

Tabela 7: Resumo das características dos PSLs estudados II 55

Tabela 8: Resumo das características dos PSLs estudados III 56 